\title{
A Technical and Economic Optimization Approach to Exploring Offshore Renewable Energy Development in Hawaii
}

\section{September 2015}

KB Larson

JD Tagestad

CJ Perkins
MR Oster

$M$ Warwick

$S$ Geerlofs 


\title{
DISCLAIMER
}

This report was prepared as an account of work sponsored by an agency of the United States Government. Neither the United States Government nor any agency thereof, nor Battelle Memorial Institute, nor any of their employees, makes any warranty, express or implied, or assumes any legal liability or responsibility for the accuracy, completeness, or usefulness of any information, apparatus, product, or process disclosed, or represents that its use would not infringe privately owned rights. Reference herein to any specific commercial product, process, or service by trade name, trademark, manufacturer, or otherwise does not necessarily constitute or imply its endorsement, recommendation, or favoring by the United States Government or any agency thereof, or Battelle Memorial Institute. The views and opinions of authors expressed herein do not necessarily state or reflect those of the United States Government or any agency thereof.

\author{
PACIFIC NORTHWEST NATIONAL LABORATORY \\ operated by \\ BATTELLE \\ for the \\ UNITED STATES DEPARTMENT OF ENERGY \\ under Contract DE-AC05-76RL01830
}

Printed in the United States of America

Available to DOE and DOE contractors from the

Office of Scientific and Technical Information,

P.O. Box 62, Oak Ridge, TN 37831-0062;

ph: (865) 576-8401

fax: $(865)$ 576-5728

email: reports $a$ adonis.osti.gov

Available to the public from the National Technical Information Service

5301 Shawnee Rd., Alexandria, VA 22312

ph: (800) 553-NTIS (6847)

email: orders $a$ ntis.gov <http://www.ntis.gov/about/form.aspx >

Online ordering: http://www.ntis.gov

This document was printed on recycled paper.

(8/2010) 


\title{
A Technical and Economic Optimization Approach to Exploring Offshore Renewable Energy Development in Hawaii
}

\author{
KB Larson \\ MR Oster \\ JD Tagestad \\ M Warwick \\ CJ Perkins \\ S Geerlofs
}

September 2015

Prepared for

the U.S. Department of Energy

under Contract DE-AC05-76RL01830

Pacific Northwest National Laboratory

Richland, Washington 99352 



\section{Summary}

This study was conducted with the support of the U.S. Department of Energy's (DOE's) Wind and Water Power Technologies Office (WWPTO) as part of ongoing efforts to minimize key risks and reduce the cost and time associated with permitting and deploying ocean renewable energy. The focus of the study was to discuss a possible approach to exploring scenarios for ocean renewable energy development in Hawaii that attempts to optimize future development based on technical, economic, and policy criteria. The goal of the study was not to identify potentially suitable or feasible locations for development, but to discuss how such an approach may be developed for a given offshore area. Hawaii was selected for this case study due to the complex nature of the energy climate there and DOE's ongoing involvement to support marine spatial planning for the West Coast. Primary objectives of the study included 1) discussing the political and economic context for ocean renewable energy development in Hawaii, especially with respect to how inter-island transmission may affect the future of renewable energy development in Hawaii; 2) applying a Geographic Information System (GIS) approach that has been used to assess the technical suitability of offshore renewable energy technologies in Washington, Oregon, and California, to Hawaii's offshore environment; and 3) formulate a mathematical model for exploring scenarios for ocean renewable energy development in Hawaii that seeks to optimize technical and economic suitability within the context of Hawaii's existing energy policy and planning.

The state of Hawaii has adopted a goal of increasing electricity use from sustainable energy resources by 70 percent from projected 2030 levels; 30 percent from energy conservation and 40 percent from renewable energy sources. Doing so faces challenges unique to Hawaii due to the fact that the majority of power demand is on Oahu and that electricity systems among the six islands are not interconnected. The so-called "Big Wind" option proposes to help meet that goal by bringing land-based wind energy from outer islands to Oahu via an undersea cable. Because this option represents competition for other energy scenarios, we used key economic underpinnings of the Big Wind project as criteria in our approach for evaluating technical and economic suitability of offshore renewable energy projects in Hawaii.

The approach presented here performs sequential analyses of technical suitability based on physical factors that affect site suitability (e.g., resource potential, depth, substrate, distance to grid infrastructure, distance to service ports) followed by an optimization process to identify some optimal combination of factors in the initial suitability assessments. We assessed technical suitability of ocean renewable energy technologies using an existing GIS model developed for similar assessments off the West Coast. The model is organized around three factors that may affect siting, including site quality, grid connection, and shore-side support. Other models of technical suitability could be applied. Next, we formulated an objective function that includes decision variables and constraining factors that affect decision space as defined by our technical and economic criteria, and attempts to find an optimal mix of energy solutions. Results of this model are not available at this time due to changes in Hawaii's energy planning and policies that occurred near the end of the project.

The approach presented here represents an initial step toward one that simultaneously considers key factors (political, economic, and technical) that affect decision making with respect to energy policy and planning. The focus of this paper is to discuss the design and configuration of the models of technical suitability and economic optimization, which are intended but not currently configured to be integrated. We provide example results from the GIS model of technical suitability and discuss future steps for integrating the models. By integrating the models it may be possible to better account for site-specific 
differences that may occur with certain parameters (e.g., technical suitability, potential capacity, utilization, cost, demand) and translate optimization model outputs into geographic representations. Similarly, it may be possible to populate the optimization model based on spatially defined scenarios for potential development. 


\section{Acknowledgments}

This project would not be possible without the financial support of the U.S. Department of Energy's (DOE's) Wind and Water Power Technologies Office (WWPTO). We would like to thank Tracy Logan of the Bureau of Ocean Energy Management (BOEM) for her guidance and helping to shape the direction of the study, and Patrick Gilman and Luke Feinberg of WWPTO for their helpful feedback on an earlier draft of this document. We also would like to acknowledge previous efforts undertaken by the DOE, Oregon Wind Energy Trust (OWET), and Parametrix that provided the methodological basis and technical understanding for assessing technical suitability in this study. Collectively, these efforts have benefitted greatly from the input of industry advisors regarding the constraints faced by developers, for which we are very grateful. 



\section{Acronyms and Abbreviations}

$\begin{array}{ll}\text { BOEM } & \text { Bureau of Ocean Energy Management } \\ \text { CMSP } & \text { Coastal and Marine Spatial Planning } \\ \text { DOE } & \text { U.S. Department of Energy } \\ \mathrm{ft} & \text { feet(foot) } \\ \mathrm{HCEI} & \text { Hawaii Clean Energy Initiative } \\ \mathrm{km}^{2} & \text { square kilometer(s) } \\ \text { LNG } & \text { liquid natural gas } \\ \mathrm{m} & \text { meter(s) } \\ \text { MIP } & \text { mixed-integer programming } \\ \text { MW } & \text { megawatt(s) } \\ \text { MWh } & \text { megawatt-hour(s) } \\ \text { NGO } & \text { nongovernmental organization } \\ \text { NM } & \text { nautical mile(s) } \\ \text { OWET } & \text { Oregon Wind Energy Trust } \\ \text { PNNL } & \text { Pacific Northwest National Laboratory } \\ \text { PSIP } & \text { Power Supply Improvement Plan } \\ \text { PUC } & \text { Public Utilities Commission } \\ \text { PV } & \text { photovoltaic } \\ \text { WEC } & \text { wave energy conversion } \\ \text { WWPTO } & \text { Wind and Water Power Technologies Office } \\ & \end{array}$





\section{Contents}

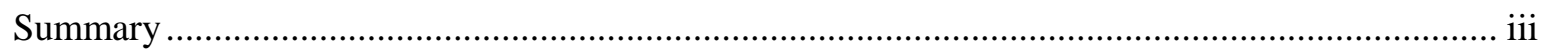

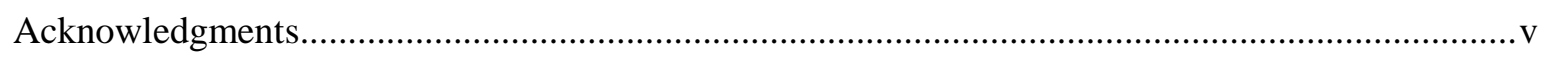

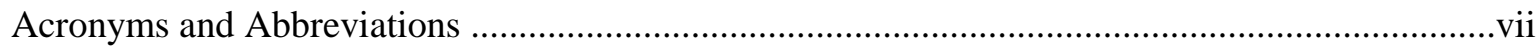

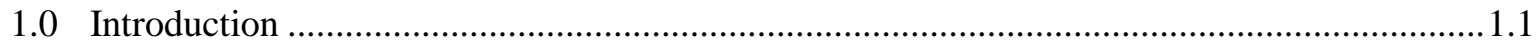

2.0 Context for Ocean Renewable Energy in Hawaii ...............................................................2. 2.1

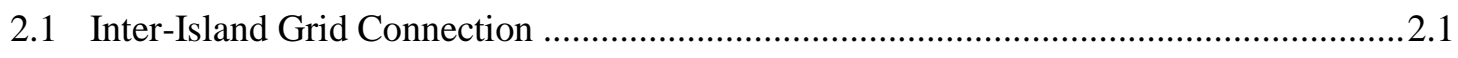

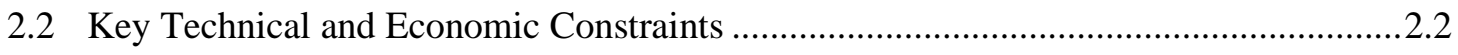

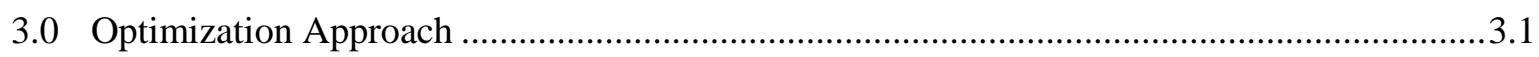

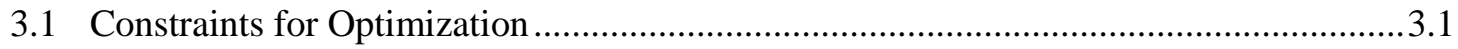

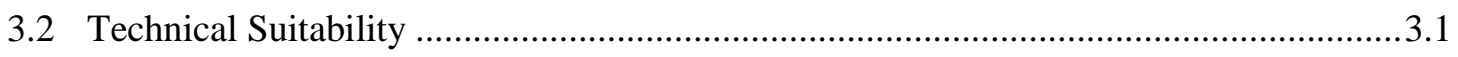

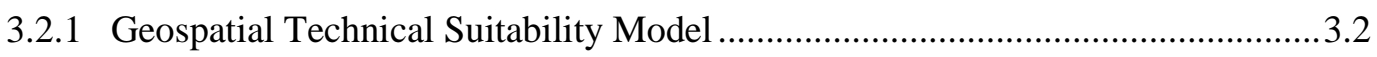

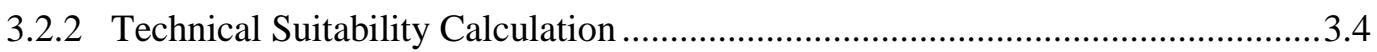

3.2.3 Preliminary Technical Suitability Results .......................................................... 3.5

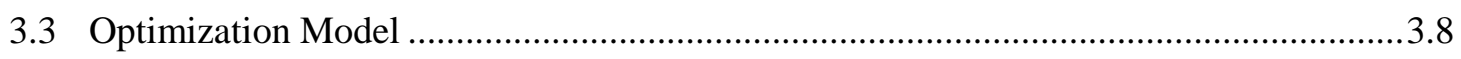

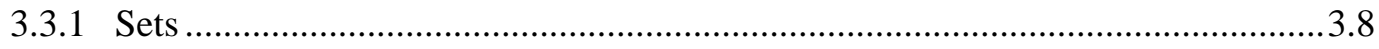

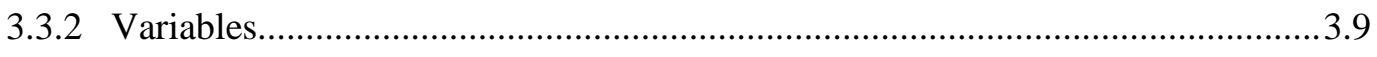

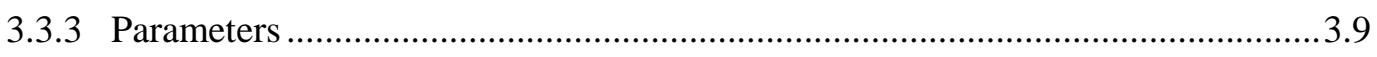

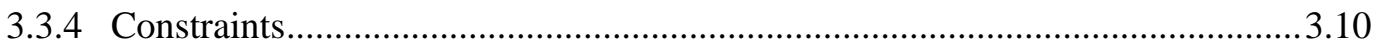

3.3.5 Objective Function ………..........................................................................

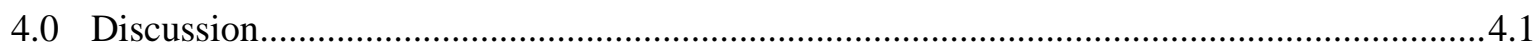

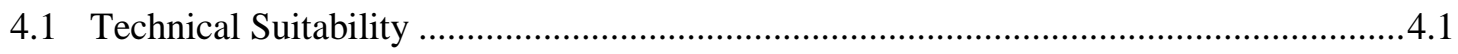

4.2 Integrating Technical Suitability and Optimization Models ........................................2

4.3 Implications of Ongoing Policy for Ocean Renewable Energy …................................4.2

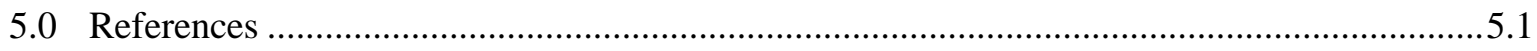




\section{Figures}

Figure 2.1. Map of the Hawaiian Islands and surrounding sea bottom......................................2.2

Figure 3.1. Framework of the geospatial technical suitability model............................................3.3

Figure 3.2. Geographic distribution of technical suitability scores for offshore floating wind

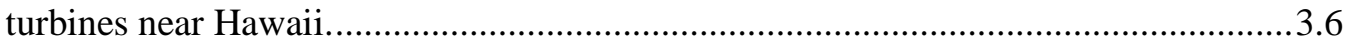

Figure 3.3. Geographic distribution of technical suitability scores for deep-water wave energy

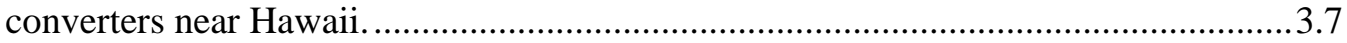

\section{Tables}

Table 3.1. Attributes of siting factors, descriptions, and summary of corresponding geospatial data used to evaluate suitability.

Table 3.2. Weighting values applied to siting factor scores for floating wind and deep-water WEC.

Table 3.3. Descriptions of variables used in optimization model.

Table 3.4. Descriptions of parameters used in optimization model.

Table 3.5. Descriptions of constraints applied to optimization model. 


\subsection{Introduction}

The U.S. Department of Energy's (DOE's) Wind and Water Power Technologies Office (WWPTO) supports research and development aimed at accelerating widespread U.S. deployment of clean, affordable, reliable, and domestic wind and water power to promote national security, economic growth, and environmental quality. An important focus of these efforts is to minimize key risks and reduce the cost and time associated with permitting and deploying ocean renewable energy. This may be done by developing tools to identify, mitigate, and prioritize environmental risks; providing data to accelerate permitting time frames and drive down costs; and engaging in Coastal and Marine Spatial Planning (CMSP) to ensure that renewable energy is considered in the nation's marine plans. This study focuses on the latter aspect and builds upon a growing body of methodology and decision-support tools intended to support national- and state-level CMSP efforts in the West Coast region, specifically for the state of Hawaii.

For the last 4 years, Pacific Northwest National Laboratory (PNNL) has worked on behalf of WWPTO to engage with agencies, industry, nongovernmental organizations (NGOs) and other stakeholders on CMSP from the perspective of ocean renewable energy. PNNL has supported DOE engagement in West Coast CMSP activities through the West Coast Governor's Agreement on Ocean Health, the Bureau of Ocean Energy Management (BOEM)/Oregon Renewable Energy Task Force, and Washington Coastal Marine Advisory Council, and attendance at other national and West Coast CMSP forums.

The nation, regions, and states are engaged in planning processes that seek to align the multiple uses of ocean space to aid management of both existing and emerging uses. Renewable energy is an emerging use that in many cases is driving planning processes. Renewable energy project developers and industry are challenged to effectively engage in CMSP processes in such a way that ongoing projects are not delayed or future opportunities precluded. CMSP has the potential to create a more rational process for siting and permitting renewable energy in the coastal zone, but it also has the potential to slow or even halt deployment and testing of renewable energy technologies.

In 2008, the state of Hawaii introduced the Hawaii Clean Energy Initiative (HCEI) in response to continued energy supply and price volatility. The HCEI established a goal of increasing electricity use from sustainable energy sources by 70 percent from projected 2030 levels; 30 percent from energy conservation and 40 percent from renewable energy sources. Doing so faces challenges unique to Hawaii due to the fact that the majority of power demand is on Oahu and that electricity systems among the six islands are not interconnected. Options to connect island transmission systems via an undersea cable are being investigated, but they are costly and would require energy imports from other islands to be large in order to justify the cost of the cable. Alternatives involving development of ocean renewable energy have been considered, but they have not been examined in the CMSP context with other alternatives. In both cases, many political, economic, environmental, technical, and social constraints will need to be considered.

This study was initiated to help support marine spatial planning efforts in the state of Hawaii, specifically by developing a technical and economic optimization approach to examining ocean renewable energy in the context of the current energy climate in Hawaii. Our objectives included the following: 
- Discuss the political and economic context for ocean renewable energy development in Hawaii, especially with respect to how inter-island transmission may affect the future of renewable energy development in Hawaii.

- Adapt and apply a Geographic Information System (GIS) approach that has been used to assess the technical suitability of offshore renewable energy technologies in Washington, Oregon, and California, to Hawaii's offshore environment.

- Develop a mathematical model for exploring scenarios for ocean renewable energy development in Hawaii that seeks to optimize technical and economic suitability within the context of Hawaii's existing energy policy and planning. 


\subsection{Context for Ocean Renewable Energy in Hawaii}

In 2008, the state of Hawaii introduced the HCEI in response to continued energy supply and price volatility due to its remote location, reliance on high-cost petroleum imports, and abundant renewable resources across the six major islands. The HCEI was developed in collaboration with the primary local electric utility, Hawaiian Electric Industries, the holding company for the three electric utilities that provide power to the islands of Oahu (HECO), Maui, Molokai, Lanai (MECO), and Hawaii (HELCO). The island of Kauai is served by an electric cooperative. The HCEI established a goal of increasing electricity use from sustainable energy sources by 70 percent from projected 2030 levels; 30 percent from energy conservation and 40 percent from renewable energy resources. Significantly, the agreement with the state of Hawaii did not include and does not bind the Hawaii Public Utilities Commission (PUC) that regulates local utilities and must approve investments agreed to under the HCEI.

Although there are abundant renewable resources across the islands, the majority of the residents and power demand are on Oahu, which is densely developed, has very high land costs, and has limited largescale renewable resources to develop. The HCEI anticipated the need to deliver power from wind farms and potentially other sources from the outer islands to Oahu via an undersea cable - the so-called "Big Wind" option. The State and others have commissioned studies of how the goals of the HCEI might be achieved. Doing so faces challenges unique to Hawaii due to the fact the six island electricity systems are not interconnected, and therefore, renewable resources cannot be shared among them.

During the writing of this report, HECO filed a revised Power Supply Improvement Plan (PSIP) that envisions a radical departure from prior plans, if embraced by the PUC, will supersede the need for an undersea cable and the Big Wind option. Consequently, the revised PSIP would significantly alter the context for ocean renewable energy development as it originally existed at the beginning of this study. The following sections are based on this earlier context which we used to establish technical and economic constraints in our study. The ongoing policy changes mentioned above are described in greater detail in Section 4.3.

\subsection{Inter-Island Grid Connection}

Previous studies suggest Oahu cannot provide 40 percent of its future generation from renewables without tying into additional renewable resources on outer islands with an undersea cable (GE and AWS). These studies estimate that only 35 percent of Oahu's future generation could come from renewables, assuming an exceptional penetration rate for rooftop solar, development of wind resources, and significant increases in use of imported biofuels (GE). Currently, there are two operating wind farms on Oahu that have a combined capacity of $99 \mathrm{MW}$ and another $66 \mathrm{MW}$ of new wind energy is proposed (i.e., $165 \mathrm{MW}$ of wind may soon be online in Oahu). Estimates of local biofuel potential indicate it could only meet about 10 percent of HECO's fuel needs, thereby requiring reliance on biofuel imports (PNNL). In light of these constraints, the Big Wind project is claimed to be essential if Oahu's electricity customers are to receive 40 percent of their power from renewables.

The Big Wind and other options sharing resources among the islands will require development of an undersea cable to tie the outer islands to the power grid on Oahu. However, an undersea cable would be costly, so access to the increased generation on outer islands would need to be financially justified and to not jeopardize grid security and reliability. Energy imports from the outer islands would have to be large 
in order to justify the cost of the cable. Although at least $600 \mathrm{MW}$ of land-based wind resource potential exists on the outer islands, HECO's grid on Oahu can only absorb 200 MW of imported energy without undue risk to reliable power supplies on Oahu. Limiting wind power imports from the outer islands to 200 MW would also increase reliance on power derived from solar photovoltaic (PV) sources and biofuel for Oahu. The project faces other barriers as well, including the technical feasibility of the cable project, economic development of outer island renewable resources, and environmental and cultural challenges.

An undersea cable from the outer islands to Oahu presents several technical challenges. For example, the distance and extreme depths between the island of Hawaii and Oahu are considered too great to consider Hawaii as a resource site for Oahu (Figure 2.1). The location of prospective large wind farms on the closest islands (Lanai, Maui, and Molokai) would dictate the route of the undersea cable to the southern and/or eastern shore of Oahu due to their location south of Oahu and the fact that HECO's major grid infrastructure is along the south shore. However, HCEI concluded that an undersea cable cannot land on Oahu's southern shore because of offshore sea bottom conditions (e.g., unexploded ordinance) and restrictions near harbors. The closest acceptable alternative landing site is on the Kaneohe Marine Corps Base on the eastern shore.

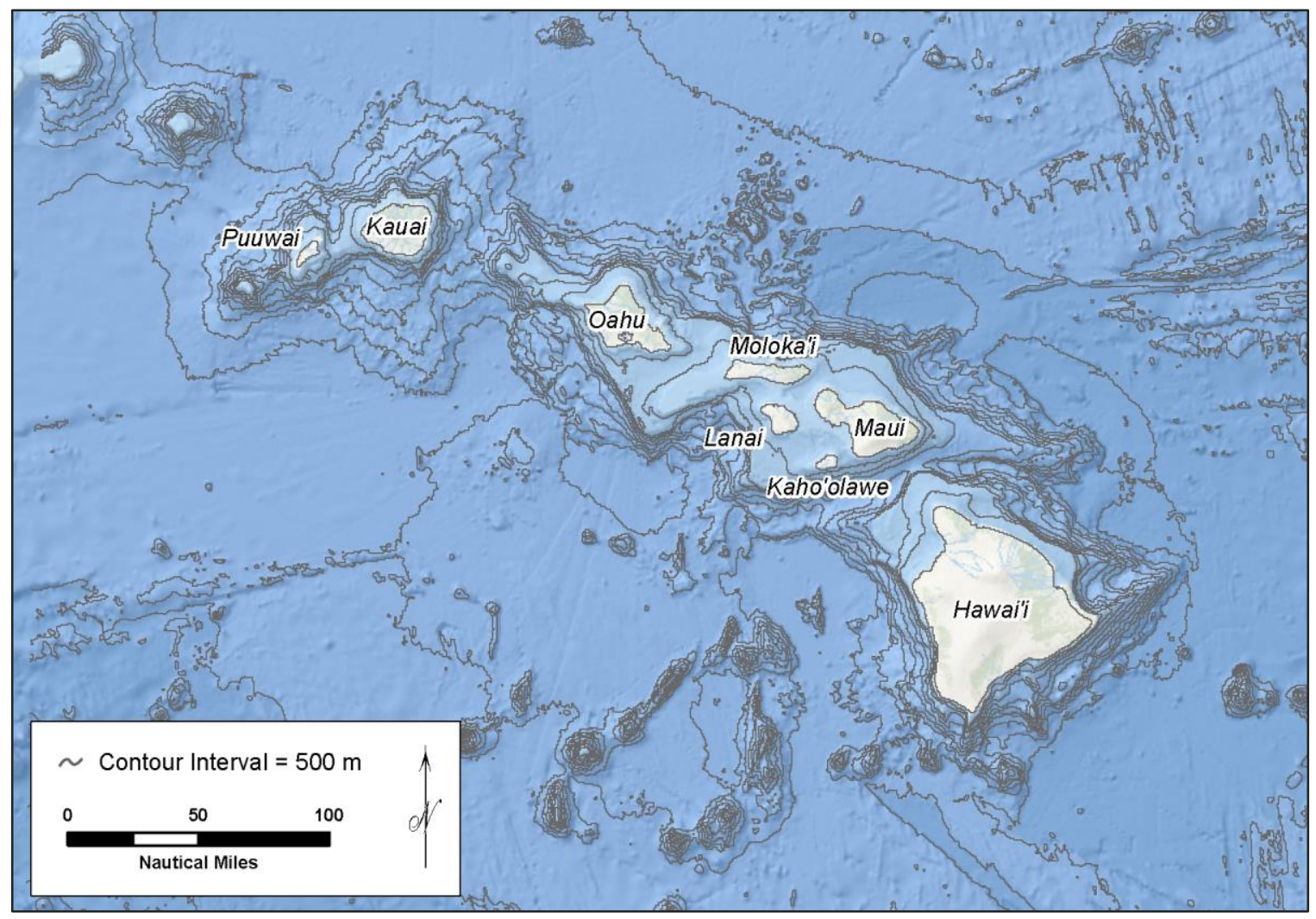

Figure 2.1. Map of the Hawaiian Islands and surrounding sea bottom.

\subsection{Key Technical and Economic Constraints}

The Big Wind project presents competition for any offshore renewable energy developments near Oahu. As previously noted, the economic assumptions underpinning analysis of the Big Wind project are based on the ability of the undersea cable to transmit at least $200 \mathrm{MW}$ of power from outer island 
projects. Development of offshore renewable energy projects near Oahu would reduce the need for the Big Wind project if they reduce power import requirements below the $200 \mathrm{MW}$ assumed in the various studies and the HCEI. Assuming $66 \mathrm{MW}$ of proposed wind energy is developed on Oahu, ocean renewable energy projects would need to provide up to $134 \mathrm{MW}$ of additional energy to offset the need for importing energy from outer islands.

Energy from offshore projects also would need to be lower cost than energy delivered from outer islands via an undersea cable to be economically competitive. The HCEI studies assume the levelized cost of energy for new projects must be less than $\$ 200 / \mathrm{MWh}$ (including cable costs) to be competitive with fossil fuel-based sources on the islands. A HECO proposal for wind power from a project on Lanai has an estimated energy cost of \$130/MWh. Given these existing factors, an offshore project near Oahu could have a $\$ 70 / \mathrm{MWh}$ spread to work with to be competitive with power from the undersea cable.

Alternatively, renewable ocean energy projects could be used to complement energy delivered from outer islands via an undersea cable if they increased the diversity of generation and capacity utilization of the undersea cable. One cable configuration under consideration could provide up to $400 \mathrm{MW}$ of capacity to Oahu using two circuits rather than one. If complementary resources have more diverse production profiles, are more predictable, and can produce power more consistently than onshore wind, those resources could use that energy potential on the outer islands and deliver it to Oahu through a higher capacity, double-circuit undersea cable. However, the ability of the HECO grid to absorb no more than 200 MW would still be a limitation. Regardless, potential ocean renewable energy projects should provide a new mix of resources that increases generation, resource diversity, and power stabilization compared to the current mix of wind and solar on Oahu. 



\subsection{Optimization Approach}

The future of offshore renewable energy development in Hawaii will depend on a suite of factors, including political and economic climate, existing and planned infrastructure, offshore resource potential, feasibility of developing offshore resources, environmental considerations, and social factors (e.g., public resistance, cultural conflicts). While it is feasible to examine each of these factors independently, decision makers must often consider multiple factors simultaneously when attempting to choose the best option. One approach to such processes is to perform sequential analyses of suitability based on key factors (e.g., technical, economic, environmental) followed by an optimization process to identify some optimal combination of factors in the initial suitability assessments.

Here, we present an approach to exploring scenarios for ocean renewable energy development in Hawaii that seeks to optimize technical and economic suitability within the context of Hawaii's existing energy policy and planning. The approach begins by examining existing energy planning and policy to determine key technical and economic constraints (Section 2.0) that must be met in the optimization analysis to achieve a feasible outcome. Next, a geospatial technical suitability model is used to calculate and map the technical suitability of the study area for available offshore energy technologies based on factors that will affect siting (e.g., energy resource, depth, sea bottom conditions, distance to grid infrastructure, and shore-side support). Finally, a mathematical model is derived that considers multiple economic factors associated with the construction, operation, maintenance, etc., of each technology type and allows users to identify an optimal mix of resources based on threshold criteria.

\subsection{Constraints for Optimization}

Review of existing energy policy and planning for Hawaii (Section 2.0) indicated that ocean renewable energy projects should meet the following criteria to be competitive with the Big Wind or other renewable energy options currently being considered: 1) deliver 134-200 MW of energy to Oahu; 2) have a levelized cost of energy of $\$ 130-\$ 200 / \mathrm{MWh}$; and 3) provide a new mix of resources that increases generation, resource diversity, and power stabilization compared to the current mix of wind and solar on Oahu. We focused our optimization approach on identifying scenarios that located ocean energy projects near Oahu because the majority of demand is on Oahu and therefore such scenarios may provide more benefit to achieving the goals of the HCEI than projects near the outer islands.

\subsection{Technical Suitability}

Given the complexity and costs associated with project construction and permitting, optimal siting of offshore wind and wave energy development areas will be crucial to making projects financially viable. Of the many factors affecting the siting of offshore wind and wave energy development, the characteristics of the energy resource, bathymetry, seabed, distance to shore, and competing uses are among the most important. Depth is a critical factor because it limits the type of technologies than can be deployed at a given location.

For offshore wind power development, fixed foundations are generally limited to shallower water. For example, monopile wind turbine foundations can be used in water depths $<30 \mathrm{~m}$, and jacket and tripod wind turbine foundations can be used in water depths $<60 \mathrm{~m}$. Floating wind platforms on mooring 
systems can be used in deeper water $(>60 \mathrm{~m})$. Because only a small proportion of the Hawaii offshore wind resource occurs in waters less than $60 \mathrm{~m}$ deep, we focused our analysis of technical suitability for wind energy on floating wind turbine platforms.

For wave energy, similar suitability constraints apply. Wave energy conversion (WEC) devices are designed to take advantage of wave energy in a range of depths, including shore-based devices designed for breakwaters and beaches, nearshore devices that convert wave surge into energy, mid-depth devices that target depths from 10-50 m, and deep-water devices that can be deployed in depths greater than $125 \mathrm{~m}$. Because most of Hawaii's wave energy resource occurs in waters $>50 \mathrm{~m}$ deep, we focused our analysis of technical suitability for wave energy on deep-water WEC devices.

\subsubsection{Geospatial Technical Suitability Model}

The technical suitability model is based closely on a model developed by Van Cleve et al. (2013a) for assessing site suitability for offshore wind and wave energy off the Washington State coast. The model has also been employed for similar assessments for the Oregon (Larson et al. 2014) and Northern California coasts (Van Cleve et al. 2013b). The model is organized around the following three factors that may affect siting (Figure 3.1):

- Site Quality. How good is the site in terms of the preferred levels of energy resource, depth, and substrate for a given technology?

- Grid Connection. What is the site's location relative to available electrical transmission and distribution infrastructure?

- Shore-Side Support. How close is the site to necessary port infrastructure for device installation, operation, maintenance, and decommissioning?

The model evaluates each of these factors at a scale equivalent to the $1200 \mathrm{~m} \times 1200 \mathrm{~m}\left(1.44 \mathrm{~km}^{2}\right)$ planning aliquots used by BOEM for leasing ocean area for energy development. For each siting factor, two to three measurable attributes are used to calculate an index value representing the relative suitability of that factor at a given aliquot. A total of eight attributes are included in the model. The attributes and scoring used to calculate suitability indices are based on input from device developers, project developers, industry coalitions, and academic experts that was solicited by Van Cleve et al. (2013a) during the initial model development and later expanded upon by Larson et al. (2014). For this initial investigation, ocean areas within 50 nautical miles (NM) of the Hawaiian Islands (approximately 196,188 $\mathrm{km}^{2}$ ) were considered for evaluation. However, complete data were available for only 18 percent $\left(35,094 \mathrm{~km}^{2}\right)$ of this area. 


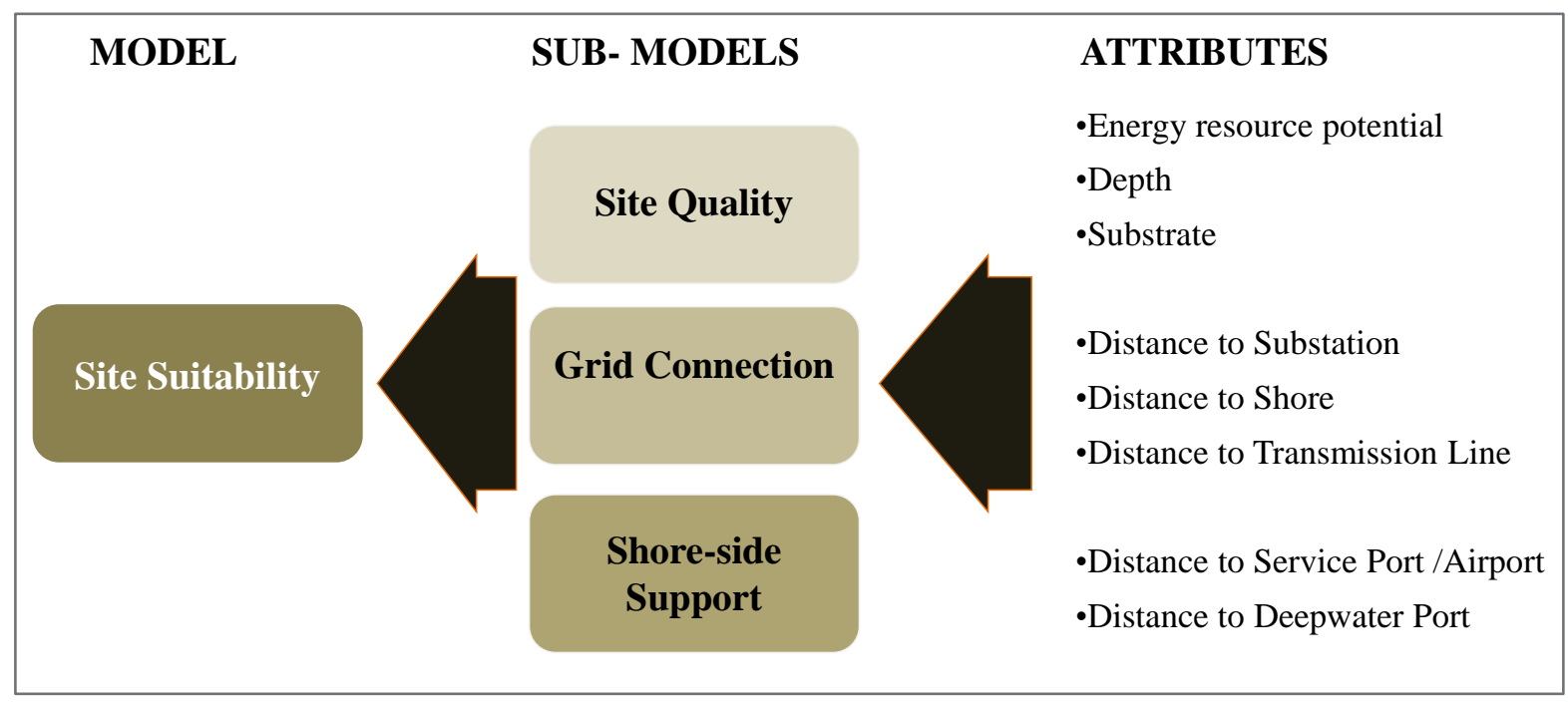

Figure 3.1. Framework of the geospatial technical suitability model.

Spatial data representing the eight attributes was acquired primarily from publicly available resources, with the exception of transmission infrastructure data (Table 3.1). Methods to spatially quantify model attributes in each aliquot were similar to those used by Van Cleve et al. (2013). Distances to shore, substations, transmission lines, and ports were based on Euclidean or straight line distance from each aliquot to the nearest feature. Although straight line distance is a simplification of assumed cable or navigation routes, it still provides a useful measure of proximity that can be used to assess site suitability.

In offshore wind development, ports serve three primary functions: component assembly, project construction and deployment, and operation and maintenance. While component assembly and project construction will likely require deep-water port access (i.e., ports with channel depths greater than $30 \mathrm{ft}$ ), operation and maintenance activities could be based out of either a deep-water port or a smaller port capable of accommodating shallow draft vessels (herein referred to as a "service port"). The scale of offshore wind turbines and challenges associated with transporting and handling turbines up to $500 \mathrm{ft}$ tall require greater specificity in defining deep-water ports with capacity to support offshore wind development. Therefore, ports with >180 m clearance were considered acceptable deep-water ports for floating offshore wind turbines. Because service activities on floating platforms would likely be performed by helicopter due to their large size and expected distances from shore, the distance to service ports was based on locations of coastal heliports and airports that have helicopter support.

Table 3.1. Attributes of siting factors, descriptions, and summary of corresponding geospatial data used to evaluate suitability.

\begin{tabular}{lll}
\hline \multicolumn{1}{c}{ Attribute } & \multicolumn{1}{c}{ Description } & \multicolumn{1}{c}{ Data Source } \\
\hline Wind Speed & Mean wind speed at 90 m & NREL 90 m offshore average wind speed \\
Wave Power Density & Power in kilowatts per meter & NREL Wavewatch III model $^{(\mathrm{b})}$ \\
Depth & $\begin{array}{l}\text { Depth from water surface to } \\
\text { seabed }\end{array}$ & $\begin{array}{l}\text { School of Ocean and Earth Science and } \\
\text { Technology }\end{array}$ \\
Substrate & $\begin{array}{l}\text { Majority substrate type on the } \\
\text { surface of the seabed. }\end{array}$ & Hawaii Statewide GIS Program $^{(\mathrm{d})}$ \\
&
\end{tabular}


Table 3.1. (contd)

\begin{tabular}{|c|c|c|}
\hline Attribute & Description & Data Source \\
\hline Distance to Shore & $\begin{array}{l}\text { Euclidean distance from site to } \\
\text { the coast }\end{array}$ & Hawaii Statewide GIS Program $^{(\mathrm{d})}$ \\
\hline Distance to Substation & $\begin{array}{l}\text { Euclidean distance from the site } \\
\text { to the nearest substation. }\end{array}$ & Homeland Security Infrastructure Program ${ }^{(\mathrm{e})}$ \\
\hline $\begin{array}{l}\text { Distance to } \\
\text { Transmission Line }\end{array}$ & $\begin{array}{l}\text { Euclidean distance from nearest } \\
\text { shore access point to the nearest } \\
\text { transmission line }\end{array}$ & Homeland Security Infrastructure Program ${ }^{(\mathrm{e})}$ \\
\hline $\begin{array}{l}\text { Distance to Service } \\
\text { Port/Airport }\end{array}$ & $\begin{array}{l}\text { Euclidean distance from the site } \\
\text { to nearest port or airport. }{ }^{(\mathrm{f})}\end{array}$ & $\begin{array}{l}\text { Hawaii Statewide GIS Program } \\
\text { Hawaii Department of Transportation }^{(\mathrm{f})} \\
\text { National Transportation Atlas Database }^{(\mathrm{g})}\end{array}$ \\
\hline $\begin{array}{l}\text { Distance to Deep- } \\
\text { Water Port }\end{array}$ & $\begin{array}{l}\text { Euclidean distance from the site } \\
\text { to nearest deep-water port. }\end{array}$ & $\begin{array}{l}\text { Hawaii Statewide GIS Program } \\
\text { Hawaii Department of Transportation }^{(\mathrm{f})}\end{array}$ \\
\hline $\begin{array}{l}\text { (a) NREL 2014a } \\
\text { (b) NREL 2014b } \\
\text { (c) SOEST 2014 } \\
\text { (d) SHOP 2014 } \\
\text { (e) HIFLD } 2014 \\
\text { (f) SHDOT } 2014 \\
\text { (g) USDOT } 2014\end{array}$ & & \\
\hline
\end{tabular}

\subsubsection{Technical Suitability Calculation}

Weighted sum algorithms were used to describe the relative suitability of sites for each offshore energy type. For each aliquot in the study area, the model performs an algorithm to calculate an index score for each siting factor and an overall suitability index score using the eight attributes described above. Index scores for site quality $(S Q)$, grid connection $(G C)$, and shore-side support $(S S)$ siting factors are calculated as follows:

$$
\text { Siting Factor Score }=\frac{\sum_{k=0}^{n}(\text { Attribute Score }) \times \text { Weight }}{\text { Potential Maximum Submodel Score } a}
$$

where $k$ indicates the lower limit and $n$ is the upper limit attribute score. The result yields an index of suitability between 0.0 and 1.0. For this study, each attribute was considered to be of equal importance (i.e., weight $=1$ ) for calculating siting factor scores. In previous studies (Van Cleve et al. 2013a, 2013b; Larson et al. 2014), industry advisors indicated that some siting factors (not attributes) were more important than others. Therefore, we applied industry-advised weights $(w)$ reported by Larson et al. (2014;

Table 3.2) to each siting factor score ( $S Q, G C, S S$ ) for each device type (a) in the calculation of the site suitability as follows:

$$
\text { Site Suitability } y_{a}=\frac{\left[\left(w_{1 a} \times S Q_{a}\right)+\left(w_{2 a} \times G C_{a}\right)+\left(w_{3 a} \times S S_{a}\right)\right]}{1}
$$


Table 3.2. Weighting values applied to siting factor scores for floating wind and deep-water WEC.

\begin{tabular}{cccc}
\hline Device Type & Site Quality $(S Q)$ & Grid Connection $(G C)$ & Shore-side support $(S S)$ \\
\hline Deep-water WEC & $45 \%$ & $27.5 \%$ & $27.5 \%$ \\
Floating Wind Turbine & $50 \%$ & $32.5 \%$ & $17.5 \%$ \\
\hline
\end{tabular}

The final site suitability score is scaled by a factor of 10 for ease of interpretation, which yields values ranging from 0 to 10 . Maps of site suitability are created by displaying planning aliquots by a graduated color scheme based on their suitability scores. Areas that did not meet a minimum suitability threshold for wind speed, wave power density, and water depth were classified as unsuitable regardless of other attribute criteria. Areas that did not have complete coverage for all eight model attributes were classified as "incomplete" rather than unsuitable.

\subsubsection{Preliminary Technical Suitability Results}

We adapted and applied the geospatial technical suitability developed by Van Cleve et al. (2013) for quantifying and mapping the technical suitability of two types of devices off the coast of Hawaii: the floating wind turbine and deep-water WEC. For the purposes of this initial view of technical suitability for the Hawaiian Islands, we used the same scoring schema applied by Larson et al. (2014) for assessing the suitability of ocean renewable energy for the Oregon Coast because it is based on recent input from industry advisors and represents a broad range of devices that are currently available or in development.

Preliminary results of the model indicate that technical suitability for floating wind turbines is generally highest along the north shores of the Hawaiian Islands, with greater concentration of high to very high suitability near the islands of Oahu, Molokai, Lanai, and Maui (Figure 3.2). Areas of high technical suitability for deep-water WEC devices are well distributed around the circumference of the Hawaiian Islands, with the exception of the island of Hawaii (Figure 3.3). With respect to Oahu specifically, the model indicates there are areas of high to very high suitability for floating wind turbines surrounding most of the island with the exception of the southwest shore, and areas of high technical suitability for deep-water WEC within 2-5 NM of the Oahu shore. Most areas within less than 2 NM from the shore were classified as unsuitable for either device type due to unsuitable or undesired depths. 


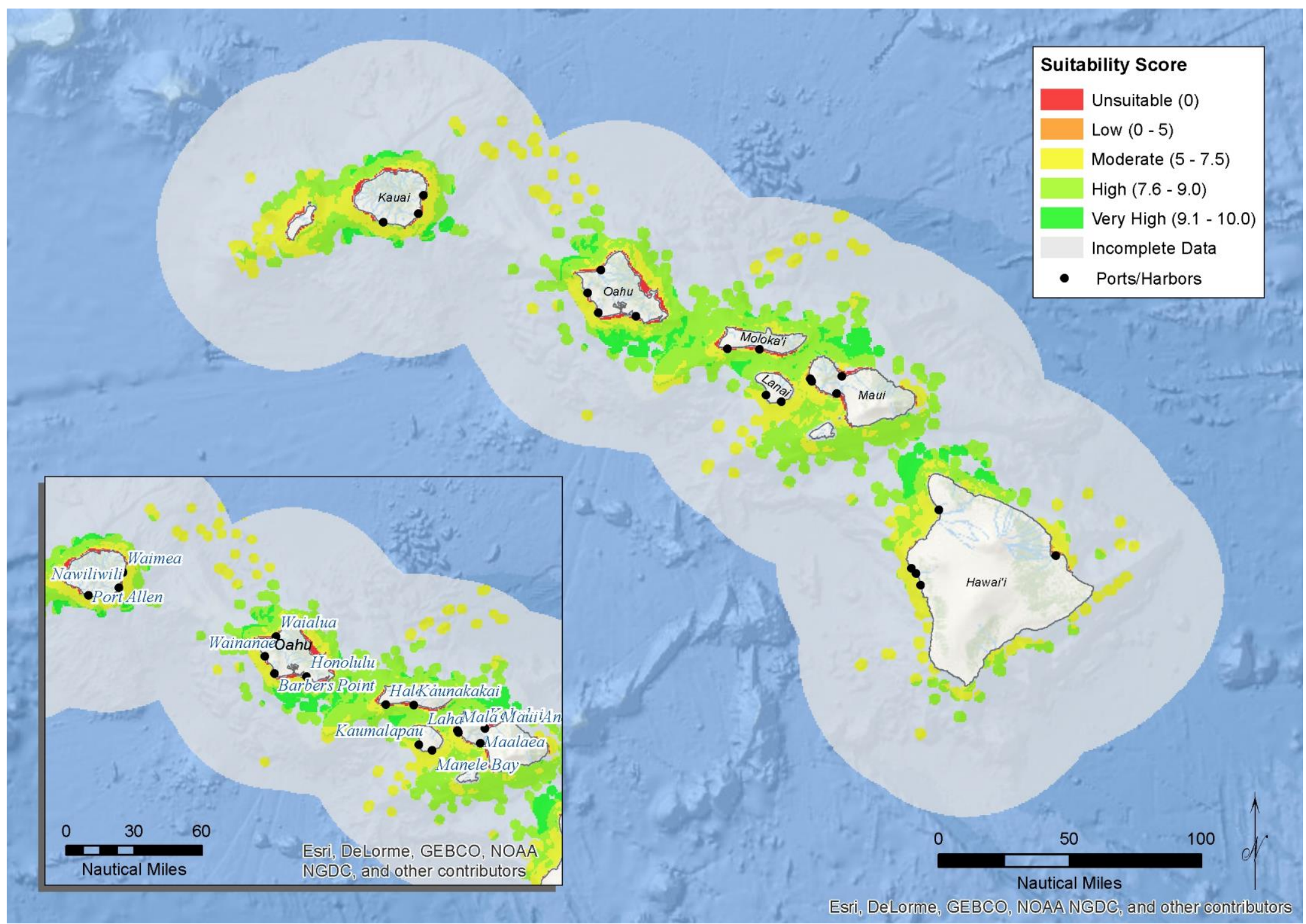

Figure 3.2. Geographic distribution of technical suitability scores for offshore floating wind turbines near Hawaii. 


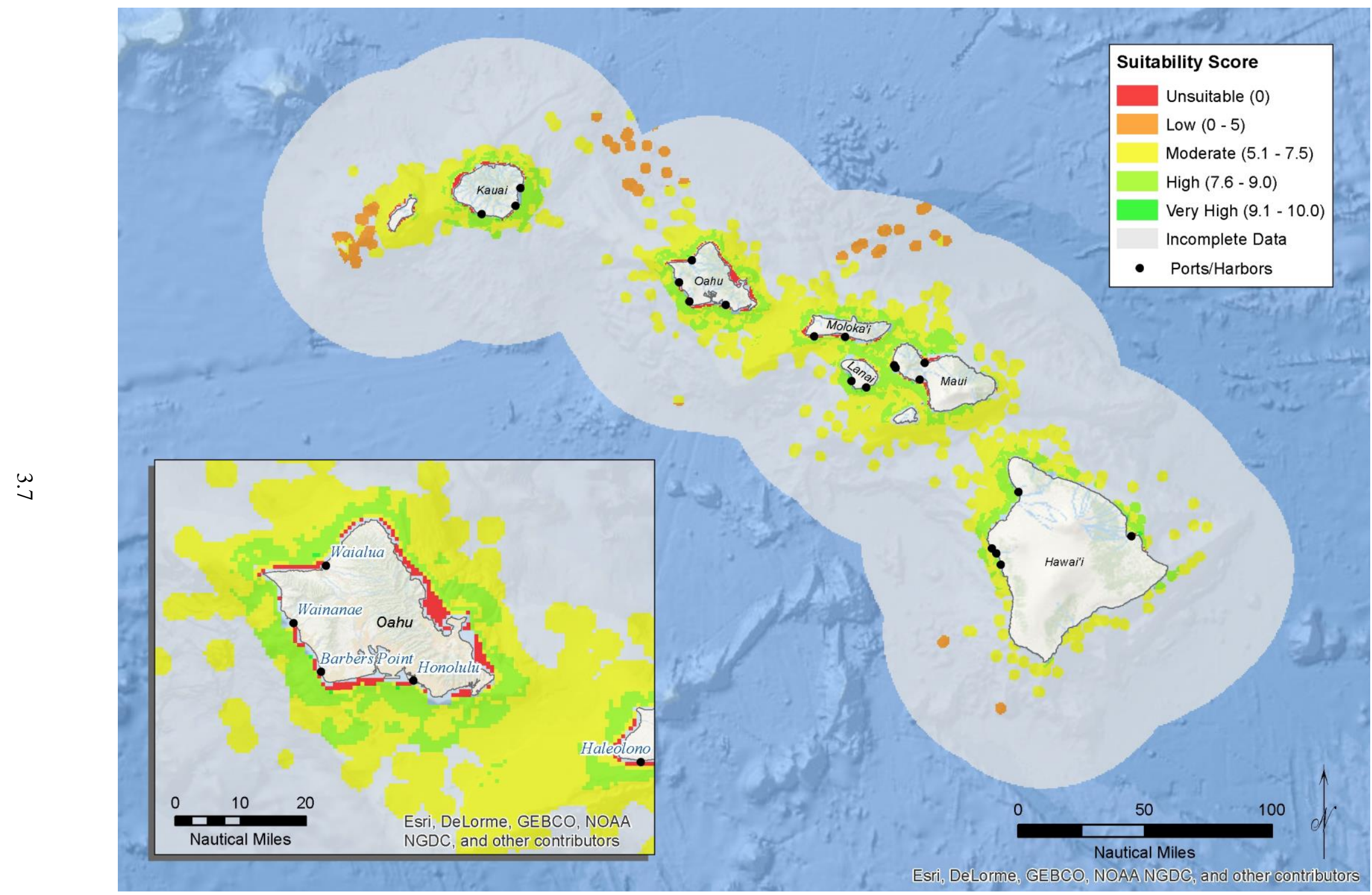

Figure 3.3. Geographic distribution of technical suitability scores for deep-water wave energy converters near Hawaii. 


\subsection{Optimization Model}

Identifying whether opportunities exist for developing ocean renewable energy in Hawaii requires simultaneous consideration of political, economic, technical, environmental, and social factors. Ideally, the goal in doing so is to identify some optimal solution that meets a mixed set of criteria associated with these factors. The approach presented here focuses on three of these key factors (political, economic, and technical) to demonstrate how an optimization approach could be used in decision making, although it could feasibly be expanded to include other considerations (e.g., environmental, social).

Before constructing the optimization model, we examined existing political and economic drivers for renewable energy in Hawaii (Section 2.0) to establish analytic criteria that must be met (Section 3.1). These criteria include the following: 1) deliver 134-200 MW of energy to Oahu; 2) have a levelized cost of energy of $\$ 130-\$ 200 / \mathrm{MWh}$; and 3) provide a new mix of resources that increases generation, resource diversity, and power stabilization compared to the current mix of wind and solar on Oahu. While additional criteria and scenarios could be developed, we chose one that reflects important decision points that could inform future discussions of ocean renewable energy development in Hawaii.

The process of constructing the optimization model begins with identifying the building blocks of the model; i.e., the "sets" over which other objects are indexed. Next, we list the variables that represent direct or indirect decisions in the model and the data elements needed to parameterize the model. Finally, we identify constraining factors that shape our decision space and formulate an objective function to find the so-called "optimal" solution to the problem. The objective function is then implemented in software using a preferred solution method (e.g., Frontline's Analytic Solver Platform and FICO Xpress solver engine from a callable spreadsheet form within Microsoft Excel.

\subsubsection{Sets}

In designing a model to explore optimal solutions for integrating ocean renewable energy with existing energy resources in Hawaii, we identified four variable sets (denoted in upper-case letters) by which objects would be indexed (denoted in similar lower-case letters):

- $T$ : technologies (renewable)

- $L$ : locations (at which renewables may be suitable for development)

- $I$ : islands (disjoint grids, each $\ell \in L$ associated with a single island)

- $E$ : subset of pairs of $I$ (pairs of islands to interconnect)

We assume that islands $i \in I$ have exactly one grid each with the optional ability to be treated as having interconnected grids. Renewable technologies $t \in T$ could be individual technologies of the same type (e.g., floating wind turbine and bottom-founded wind turbine), distinct types (e.g., wind turbine and wave energy converter), or similar technologies held by different contractors differing only in estimated prices or total potential capacities, for example. Each development location $\ell \in L$ is associated with one island and has the option of being associated with multiple islands having interconnected grids. 


\subsubsection{Variables}

After identifying the variable sets we select key variables to represent those sets in the model. The model includes two types of variables: 1) binary variables (e.g., yes/no decision to build an interconnection between islands or build a new renewable technology at a given location); and 2) continuous variables (e.g., capacity of new renewable devices, capacity of existing energy resources, annual energy produced) (Table 3.3). These variables can be parameterized by the user as they see fit. For example, we can decide how much capacity to provide to a technology type at any location based on resource potential or maximum number of devices that can be built in a given location.

Table 3.3. Descriptions of variables used in optimization model.

\begin{tabular}{ccc}
\hline $\begin{array}{c}\text { Variable } \\
\text { Type }\end{array}$ & $\begin{array}{c}\text { Variable } \\
\text { Notation }\end{array}$ & Variable Description \\
\hline $\begin{array}{c}\text { Decision/ } \\
\text { Binary } \\
\text { Variables }\end{array}$ & $x_{i j}^{w}$ & decision (0/1) to build new interconnection (wire) between $i$ and $j$ where $\{i, j\} \in E$ \\
\hline & $x_{\ell t}$ & decision (0/1) to build new renewable technology $t \in T$ at location $\ell \in L$ \\
$\begin{array}{c}\text { Capacity- } \\
\text { based }\end{array}$ & $\hat{y}_{\ell t}^{r}$ & capacity (MW) to build new renewables $t$ at $\ell$ \\
& $\hat{p}_{i}^{r}$ & total renewable capacity (MW) of both new and existing sources at $i$ \\
& $\hat{y}_{i}^{o}$ & capacity (MW) of oil-based power at $i$ \\
\hline $\begin{array}{c}\text { Total } \\
\text { Energy- } \\
\text { based }\end{array}$ & $y_{i j}^{w}$ & total yearly energy (MWh) sent from island $i$ to $j$ where $\{i, j\} \in E$ \\
& $y_{\ell t}^{r}$ & total yearly energy (MWh) produced by new renewables $t$ at $\ell$ \\
& $p_{i}^{r}$ & total yearly energy (MWh) produced by existing renewables at $i$ \\
& $y_{i}^{o}$ & total yearly energy (MWh) produced by oil at $i$
\end{tabular}

\subsubsection{Parameters}

Once all of the model variables have been identified we can begin to parameterize the model. The model includes four types of parameters: 1) availability/capacity; 2) utilization; 3) cost; and 4) demand (Table 3.4). Some assumptions pertaining to these parameters are that a maximum capacity can be measured or estimated for each power source, utilization can be estimated by dividing a power source's expected amount of energy production by the maximum possible output over a given time period, and demand quantities and requirements are fixed for a period of time. Cost parameters include both one-time incurred costs (e.g., construction, initial linking to a grid connection point) and levelized costs one must charge per energy unit (MWh) to break even due to labor, maintenance, or constant production. All levelized costs in the initial model design assume a linear relationship between operating cost and energy production, although non-linear cost relationships can be applied. 
Table 3.4. Descriptions of parameters used in optimization model.

\begin{tabular}{|c|c|c|}
\hline $\begin{array}{l}\text { Parameter } \\
\text { Type }\end{array}$ & $\begin{array}{c}\text { Parameter } \\
\text { Notation }\end{array}$ & Parameter Description \\
\hline \multirow{6}{*}{$\begin{array}{l}\text { Availability/ } \\
\text { Capacity Data }\end{array}$} & $a_{i j}^{w}$ & availability ( $0 / 1)$ of new interconnection (wire) construction between $i$ and $j$ \\
\hline & $a_{\ell t}$ & availability $(0 / 1)$ of renewable technology $t$ at location $\ell$ \\
\hline & $\hat{m}_{i}^{w}$ & max capacity (MW) of any interconnection coming into $i$ \\
\hline & $\hat{m}_{\ell t}$ & max capacity (MW) of new renewables $t$ at $\ell$ \\
\hline & $\hat{m}_{i}^{r}$ & max capacity (MW) of existing renewables at $i$ \\
\hline & $\hat{m}_{i}^{o}$ & max capacity (MW) of oil-based power at $i$ \\
\hline \multirow{3}{*}{$\begin{array}{l}\text { Utilization } \\
\text { Factors }\end{array}$} & $u_{\ell t}$ & utilization factor (\%) of new renewables $t$ at $\ell$ \\
\hline & $u_{i}^{r}$ & utilization factor (\%) of existing renewables at $i$ \\
\hline & $u_{i}^{o}$ & utilization factor (\%) of oil-based power at $i$ \\
\hline \multirow{5}{*}{$\begin{array}{c}\text { Cost } \\
\text { Elements }\end{array}$} & $c_{i j}^{w}$ & one-time cost of building new interconnection between $i$ and $j$ \\
\hline & $c_{\ell t^{\prime}}$ & one-time cost of building new renewables $t$ at $\ell$ \\
\hline & $c_{\ell t}$ & levelized cost of energy ( $\$ / \mathrm{MWh}$ ) produced by new renewables $t$ at $\ell$ \\
\hline & $c_{i}^{r}$ & levelized cost of existing renewables (\$/MWh) at $i$ \\
\hline & $c_{i}^{o}$ & levelized cost of oil-based power ( $\$ / \mathrm{MWh})$ at $i$ \\
\hline \multirow{3}{*}{$\begin{array}{c}\text { Demands/ } \\
\text { Requirements }\end{array}$} & $\hat{d}_{i}$ & peak demand (MW) for power at $i$ \\
\hline & $d_{i}$ & total demand (MWh) for power at $i$ \\
\hline & $q^{r}$ & total/minimum percentage $(\%)$ of demand to be from renewables \\
\hline
\end{tabular}

\subsubsection{Constraints}

A variety of constraints are applied to model variables to provide rules for when decisions are made to build an interconnection or renewable technology at a particular location, how much capacity can be developed, how much energy can be produced or shared among islands, and how demand influences development (Table 3.5). Capacity constraints establish thresholds for how much capacity can be developed based on how much resource is available. Similar constraints are applied for how much energy can be produced in a year based on capacity and utilization. Because the model considers energy for multiple islands and potential interconnections among islands, aggregate constraints are also included in the model for how much energy can be produced or shared among islands. Demand is constrained by total demand for all islands, which must be met exactly. As currently constructed, the model does not include energy savings obtained by conservation or reductions in fossil-fuel-based energy production. 
Table 3.5. Descriptions of constraints applied to optimization model.

\begin{tabular}{|c|c|}
\hline Constraint Type & Constraint Equation/Description \\
\hline Decision/Binary & $\begin{array}{l}x_{i j}^{w}=x_{j i}^{w} \in\{0,1\} \\
x_{\ell t} \in\{0,1\} \\
x_{i j}^{w} \leq a_{i j}^{w} \\
x_{\ell t} \leq a_{\ell t} \\
\sum_{t} x_{\ell t} \leq 1 \text { (no more than } 1 \text { technology per location) }\end{array}$ \\
\hline Capacity & $\begin{array}{l}0 \leq \hat{y}_{\ell t} \leq \hat{m}_{\ell t} \cdot x_{\ell t}(\text { can only add capacity if deciding to build }) \\
0 \leq \hat{y}_{i}^{r} \leq \hat{m}_{i}^{r} \\
0 \leq \hat{y}_{i}^{o} \leq \hat{m}_{i}^{o}\end{array}$ \\
\hline $\begin{array}{l}\text { Capacity \& Total } \\
\text { Expected Energy } \\
\text { Production }\end{array}$ & $\begin{array}{l}0 \leq y_{i j}^{w} \leq 8760 \cdot \hat{m}_{i j}^{w} \cdot x_{i j}^{w} \\
y_{\ell t}=8760 \cdot u_{\ell t} \cdot \hat{y}_{\ell t} \\
y_{i}^{r}=8760 \cdot u_{i}^{r} \cdot \hat{y}_{i}^{r} \\
y_{i}^{o}=8760 \cdot u_{i}^{o} \cdot \hat{y}_{i}^{o}\end{array}$ \\
\hline $\begin{array}{l}\text { Aggregate renewable } \\
\text { capacity/production }\end{array}$ & $\begin{array}{l}\hat{p}_{i}^{r}=\sum_{\ell \in i} \sum_{t} \hat{y}_{\ell t}+\hat{y}_{i}^{r} \\
p_{i}^{r}=\sum_{\ell \in i} \sum_{t} y_{\ell t}+y_{i}^{r} \\
\hat{t}_{i}=\hat{p}_{i}^{r}+\hat{y}_{i}^{o} \\
t_{i}=p_{i}^{r}+y_{i}^{o}+\sum_{j \neq i} y_{j i}^{w}-\sum_{j \neq i} y_{i j}^{w}\end{array}$ \\
\hline Demand & $\begin{array}{l}\hat{t}_{i} \geq \hat{d}_{i} \text { (meet or exceed demand) } \\
t_{i}=d_{i}(\text { meet demand but do not exceed }) \\
\sum_{i} p_{i}^{r} \geq q^{r} \cdot \sum_{i} d_{i} \text { (meet the global percentage renewable threshold) }\end{array}$ \\
\hline
\end{tabular}

\subsubsection{Objective Function}

The development of the optimization model is concluded with the formulation of the objective function that seeks to minimize cost while considering all applicable constraints. The initial optimization model was formulated as follows:

$$
P=\sum_{\{i, j\} \in E} c_{i j}^{w} x_{i j}^{w}+\sum_{\ell, t} c_{\ell t} x_{\ell t}+\sum_{\ell, t} c_{\ell t} y_{\ell t}+\sum_{i} c_{i}^{r} y_{i}^{r}+\sum_{i} c_{i}^{o} y_{i}^{o}
$$


The optimization problem formulated in $P$ assumes that the primary goal of all entities incurring cost is meeting the renewable requirements and minimizing cost is a secondary objective.

Many solution methods exist for implementing the type of complex objective function described above. Employing a mixed-integer programming (MIP) model of the problem that can be implemented using a general MIP solver would be tractable and accessible. There are both free and commercial MIP solvers available that can handle such problems. 


\subsection{Discussion}

This report presents an approach to exploring scenarios for ocean renewable energy development in Hawaii that seeks to optimize technical and economic suitability within the context of existing energy policy and planning. The approach involves examining existing energy policy and planning to determine key technical and economic constraints, determining potentially suitable areas for development using a geospatial technical suitability model that considers factors that affect siting (e.g., energy resource, depth, sea bottom conditions, distance to grid infrastructure and shore-side support), and evaluating multiple economic factors associated with construction, operation, and maintenance of offshore renewable energy devices to identify an optimal mix of resources based on key technical and economic criteria. The following sections discuss application of the geospatial technical suitability model (Section 4.1), benefits of integrating the technical suitability and optimization models (Section 4.2), and implications for ocean renewable energy based on new developments in Hawaii's energy policy that have taken place since the time of this initial investigation (Section 4.3).

\subsection{Technical Suitability}

Because of the complexity and costs associated with project construction and permitting, optimal siting of ocean renewable energy development areas will be crucial to making projects financially viable. The geospatial technical suitability model presented here provides a relatively rapid method for making large-scale assessments of potentially suitable areas for ocean renewable energy based on physical factors that affect site suitability (e.g., resource potential, depth, substrate, distance to grid infrastructure, distance to service ports). Although the model is based on factors that affect suitability from a technical standpoint, it can easily be modified to include other types of factors that affect site suitability such as environmental sensitivity, commercial or recreational importance, and ocean transportation.

The suitability model is also flexible in how it can be implemented. For example, individual model attributes can be scored and weighted differently based on their perceived level of importance by the user. We used scores and weights based on input gathered by Larson et al. (2014) from members of the ocean renewable energy industry, which were grouped by like types of devices. However, this approach may not describe site suitability as well for individual devices based on their unique requirements. If desired, the suitability model can be implemented for specific types of devices. Similarly, the model can be updated to reflect changes in available technologies, deployment constraints, and data availability.

Methods for viewing the model results are also flexible. Although the maps presented here show different categories of suitability, the data underlying them are continuous (with the exception of substrate type) and thus the boundaries between one suitability class and the next should be considered "fuzzy." Suitability scores can be grouped into classes or displayed continuously based on a user's preferences. Although most of the underlying data are continuous, the scale at which most input data sets are developed does not support site-scale analysis. Rather, the suitability model is intended for identifying areas within coastal regions that may be more appropriate for development and may require additional site characterization. 


\subsection{Integrating Technical Suitability and Optimization Models}

The approach presented here represents an initial step toward one that simultaneously considers key factors (political, economic, and technical) that affect decision making with respect to energy policy and planning. Future steps to achieving this should consider integrating the technical suitability and economic optimization models to better represent interactions between site suitability, site availability, and economic drivers. Currently, the models are configured to function independently, but they are capable of providing complementary information to each other. For example, the technical suitability model can be used to determine a maximum number of potential locations considered in the optimization model (presumably above some threshold of technical suitability) where renewable energy could be built. However, the optimization currently does not account for site-specific differences that may occur with certain parameters (e.g., technical suitability, potential capacity, utilization, cost, demand). By integrating the models it may be possible to better account for such differences and translate optimization model outputs into geographic representations. Similarly, it may be possible to populate the optimization model based on spatially defined scenarios for potential development. For example, a user may be able to select one or more areas of interest on a map based on technical suitability or some other set of factors and determine an "optimal" solution for those areas based on the optimization model output.

\subsection{Implications of Ongoing Policy for Ocean Renewable Energy}

In August 2014, HECO filed a revised Power Supply Improvement Plan (PSIP) in response to the PUC's rejection of its previous plans. The revised PSIP envisions a radical departure from prior plans and, if embraced by the PUC, will supersede the need for an undersea cable and the Big Wind option. Consequently, the revised PSIP would significantly alter the context for ocean renewable energy development as outlined in Section 2.0.

The revised PSIP measures success by the fraction of renewables and customer bill levels in 2030 rather than the periods in between. The PSIP assumes over 65 percent of the power will be from renewable sources by 2030 and customer bills will be 27 percent lower than under the business as usual case, which assumes continued use of liquid fuels, petroleum at global market prices, and biofuel at a premium over fossil-fuel prices. The new PSIP makes several important assumptions, including the following: 1) imports of liquid fuels will be mostly replaced by imports of liquid natural gas (LNG) on all islands; 2) demand will decrease by approximately 30 percent due to increases in energy efficiency/conservation and customer-owned solar power; 3 ) offshore wind energy (floating platform) will not be commercially ready until 2020 ; and 4) wave energy will not be commercially ready in time to meet HECO's goals.

These changes from the current strategy would have important implications with respect to technical and economic constraints for examining optimal scenarios for ocean renewable energy in Hawaii. Instead of competing with the Big Wind option, ocean renewable energy would have to compete with a system that relies on interactions with customer-owned renewables (primarily solar and onshore wind), energy storage, and more responsive generators fueled with LNG. If demand is greater than projected, HECO will need to procure power from new renewable sources and/or increase the fleet of conventional generators operating on either LNG or biofuel. However, HECO assumes that offshore wind or wave energy would not be commercially available as potential sources to supplement supply. 


\subsection{References}

HIFLD (Homeland Infrastructure Foundation-Level Working Group). 2014. Homeland Security Infrastructure Program (HSIP). Available online at: https://www.hifldwg.org/hsip-guest.

Larson K, J Tagestad, S Geerlofs, M Sanders, J Ahmann, J Busch, and B Van Cleve. 2014. Offshore Wind and Wave Energy Feasibility Mapping for the Outer Continental Shelf off the State of Oregon. BOEM 2014-658, Bureau of Ocean Energy and Management, Pacific OCS Region, Camarillo, California.

NREL (National Renewable Energy Laboratory. 2014a. Dynamic Maps, GIS Data, \& Analysis Tools, Wind Data. Available online at: http://www.nrel.gov/gis/data_wind.html.

NREL (National Renewable Energy Laboratory). 2014b. Dynamic Maps, GIS Data, \& Analysis Tools, Marine \& Hydrokinetic Data. Available online at: http://www.nrel.gov/gis/data_mhk.html

SHDOT (State of Hawaii Department of Transportation). 2014. Port Hawaii Commercial Harbors System Handbook. Available online at: http://hidot.hawaii.gov/harbors/library/port-hawaii-handbook/.

SHOP (State of Hawaii Office of Planning. 2014. Hawaii Statewide GIS Program. Available online at: http://planning.hawaii.gov/gis/.

SOEST (School of Ocean and Earth Science and Technology. 2014. Main Hawaiian Islands Multibeam Bathymetry and Backscatter Synthesis. Available online at: http://www.soest.hawaii.edu/HMRG/multibeam/index.php.

USDOT (U.S. Department of Transportation). 2014. National Transportation Atlas Database. USDOT Research and Innovative Technology Administration, Bureau of Transportation Statistics. Available online at: http://www.rita.dot.gov/bts/sites/rita.dot.gov.bts/files/publications/ national_transportation_atlas_database/index.html.

Van Cleve FB, C Judd, A Radil, J Ahmann, and SH Geerlofs. 2013a. Geospatial Analysis of Technical and Economic Suitability for Renewable Ocean Energy Development on Washington's Outer Coast. PNNL-22554, Pacific Northwest National Laboratory, Richland, Washington.

Van Cleve FB, KB Larson, JD Tagestad, AE Copping, and SH Geerlofs. 2013b. Geospatial Analysis of Technical and Economic Suitability for Offshore Wind Energy off Northern California. PNNL-23034. Pacific Northwest National Laboratory, Richland, Washington. 


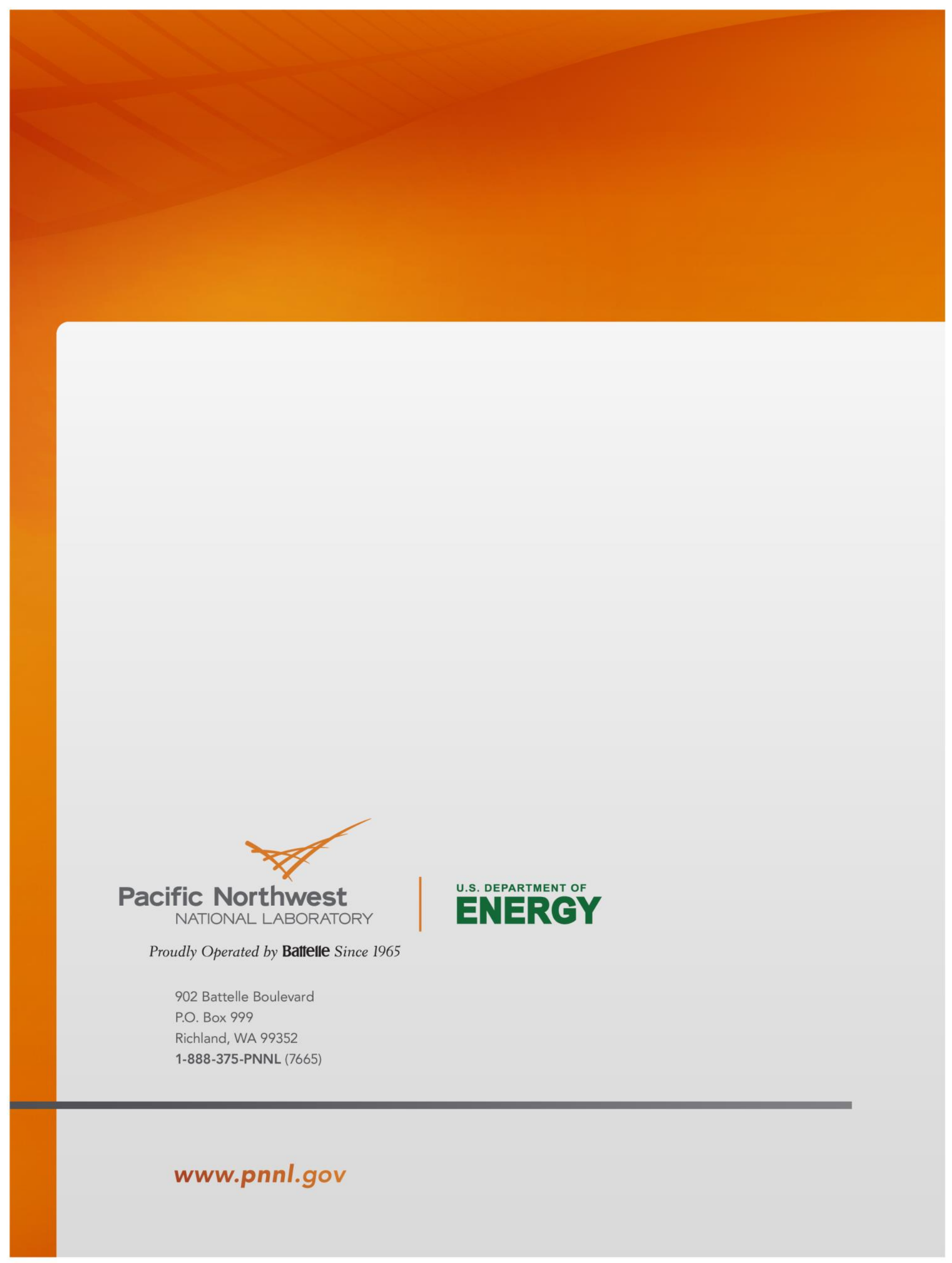

